\title{
INSTALLATION AND ANALYSIS OF SENSORS USED IN THE FULL SCALE TEST TRACK OF THE ROAD STUDIES CENTRE (CEDEX)
}

\author{
Bernardo Mingo Villalobos. Ing. Industrial. \\ Laboratorio de Instrumentación del CEC.CEDEX.bmingo@cedex.es \\ Javier Pérez Ayuso. Diplomado en Arquitectura. \\ Laboratorio de Instrumentación del CEC.CEDEX.jayuso@cedex.es \\ Javier Aleixandre Campos. Licenciado en Ciencias Físicas. \\ Sector de Técnicas Físicas y Electrónicas.CETA.CEDEX.j.aleixandre@cedex.es \\ José Bueno Pérez. Dr. Ing. Naval. \\ Sector de Técnicas Físicas y Electrónicas.CETA.CEDEX.j.bueno@cedex.es \\ Jaime Tamarit Rodriguez. Dr. en Ciencias Físicas. \\ Sector de Técnicas Físicas y Electrónicas.CETA.CEDEX. Jaime.Tamarit@cedex.es
}

\begin{abstract}
One internationally accepted definition of pavements test uracks defines them as "those facilities devoted to the study of problems related to the structural dimensioning of roads pavements". That the pavements are tcsted at real scale, that they are tested in accelerated way and with controlled loads has to be added to complete this definition.

The Spanish facility was inaugurated in 1988 and is owned by the Centre of Roads Studies from CEDEX. It is located at "El Goloso", near Madrid.
\end{abstract}

The aims of this facility are the following:

- Experimental determination of stress and strain pavement parameters characterising the response of a pavement to a load. This characterisation is accomplished thanks to the use of embedded sensors.

$>$ Characterisation of the pavement behaviour changes due to load application (slope of load application, distance to load application...etc) and environmental conditions (environment temperature, moisture...etc).

$>$ Sensors fitting for the instrumentation of different materials used in roads construction.

This communication is completed with other presented to this Congress and entitled: "Data acquisition real-time system for the fast testing facility of the Centre of Roads' Studies of CEDEX".

Keywords: Roads, Instrumentation, Sensors, Computer-aided analysis, Experimental Data Base.

\section{DESCRIPTION OF THE TEST FACILITY}

There are two well known kinds of test facilitics: circular and linear shaped. The Spanish one is in between, having two straight sections of $75 \mathrm{~m}$ each, joined by two additional curved sections (See Fig 1.).

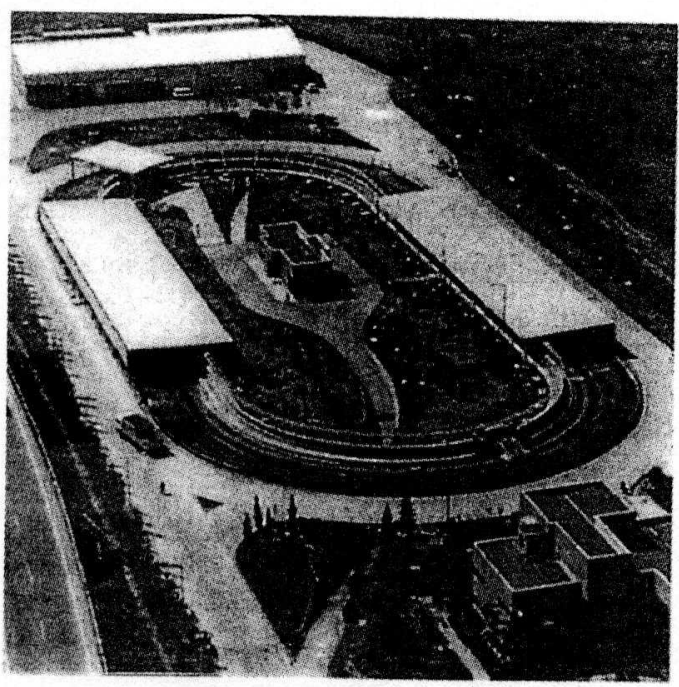

Fig 1: Roads' Test Facility at CEDEX
Considering that the six sections of pavements under test are installed on the straight segments of the track, this facility could be classified from the test point of vicw inside the second group of linear-shaped facilities. The total length travelled by the load test wheel is of 304 meters by cycle. The curved segments are not used for test purposes and are assigned to other studics like surface materials, surface treatments, paints wearing paths, etc.

Meanwhile the curved segments are based on the terrain, the straight segments are installed inside two watertight $U$ shaped lanks made out of reinforced concrete. The inner transversal dimensions of these tanks are of $8 \mathrm{~m}$ width by $2,6 \mathrm{~m}$ deep. This allows the test of $1.25 \mathrm{~m}$ high cmbankments so as the control of the phreatic levels insidc the tanks. This configuration also allows the use of conventional machinery for roads construction.

Over the two straight segments, a metallic roof has been installed to cover all test sections. Rain effects can be also simulated by means of water norzles installed on the test sections.

The two test vehicles apply the load by gravity through a half heavy axle. The load can be fixed in between 5.5 and 
7.5 Tons and is fixed at 6.5 Tons, equivalent to the maximum allowed load in Spain for a single axis (13 Tons).

The suspension system is pneumatic. The test wheel is equipped with two twin wheels or one single balloon-shaped wheel at $8,5 \mathrm{Kg} / \mathrm{cm}^{2}$ inflating pressure. Both the suspension system so as the traction test wheel are conventional ones used in Roads' Transport. The circulating speed is of 40 $\mathrm{Km} / \mathrm{h}$, with a maximum allowable speed of $60 \mathrm{Km} / \mathrm{h}$.

Thanks to an hydraulic actuator, the test wheel can bc positioned in seven different transversal paths, producing in this way a footprint band of 1.0 to $1.3 \mathrm{~m}$ width. The automatic control of this position allows to reproduce a real statistical distribution of passages according to real traffic.

This test facility is fully controlled from a centralised Control Centre, situated in the geometrical centre of the test track. The control programme has been specifically developed for this application. The control commands are transmitted by cable and received by sliding contacts. In this way the whole facility can work unattended once programmed. The test frequency is higher than $1 \times 10^{6}$ cycles by year.

The automation process was mainly considered during the design phase of the facility with the aim of reaching an test life cycle with minimum interruptions.

All the installation has been developed in Spain. The tcst vehicles, its control system and the data acquisition systems have been specially designed for this application.

\section{MEASURING PARAMETERS AND INSTRUMENTATION PLAN.}

When a wheel travcls over the surface along a real road, stresses and strains are produced in any point ahead the applied load, their magnitude depend on several parameters as are the magnitude and direction of application of the load, the pavement configuration, the type of esplanade in the base, the temperature, decpness of the element into consideration, etc. Obviously, the magnitudes of the stresses to which the road elements are submitted are far away below of the breaking point. Nevertheless, failures appear becausc of the cyclic application of the load, raising fatigue phenomena in the constituent materials.

The pavements' instrumentation allows to measure stresses and strains appearing in different points of the firm under load application. This instrumentation will be focused in those points considered as critical.

The mechanical strain / stress behaviour is different for each layer, made out with constituent materials. For this reason, it is necessary to differentiate sensors for different magnitudes and measuring points.

The bituminous mixtures supported by granular materials fail because of the accumulation of horizontal traction strains in the bottom of the bituminous layer. Accordingly, the instrumentation of this layer aims at the measurement of horizontal strains in the direction of the movement and in the direction normal to the application of the load, in the bottom of the layer.
Thanks to the contact between its constituent particles, the granular layers are able to distribute around the stress produced by the load application. Failures appear because of the partial erosion and readjusting of its mineral particles. For this reason the instrumentation of this layers is focused on the measurement of the normal strains in the upper sheets of this type of layers.

With the aim of calibrating mathematical models and carrying out analysis of different clasticity coefficients, spccific sensors have been placed on this sheet of the granular layers, cnabling the measuring of normal pressurcs transmitted there.

To obtain data related to the fatigue of the constituent materials of each layer, other sensors are installed to follow up the cvolution of each type of pavement. These measures are carried out by using displacement sensors, detecting normal displacements at the surface of the pavement. These sensors are installed on the surface of the pavement, with the sensor extrcmity fixed to the concrete bank, in the bottom of the track.

Lastly, a group of sensors are installed to detect the evolution of other magnitudes like temperature, phreatic level of cach scetion and moisture, which are fundamental for the correct analysis of the data provided by the remaining sensors.

Once the decision has been taken about the magnitudes to measure and the layers where they are going to be measured, next step consist on the location of each sensor inside each instrumented section. After the analysis of the advantages and drawbacks of different configuration possibilities, it was decided for the present test to spread the sensors along two meters along the central axis of each section instead of distributing them along the whole section. The normal distribution plan was elected to be coincident with the centre of vehicle's footprint path.

Next figure shows the longitudinal sensors' distribution of an instrumented section (Section 2).

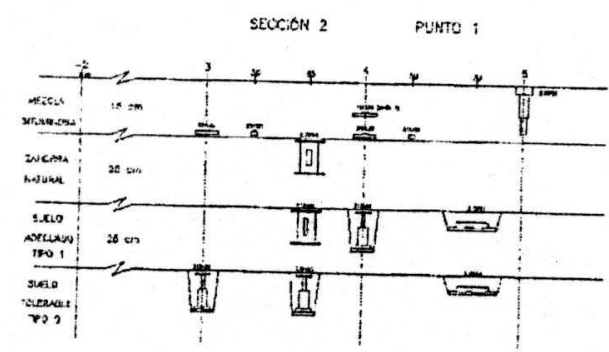

Fig 2: Longitudinal instruments' distribution of section 2.

\section{DATA ACQUISITION SYSTEM}

The Data Acquisitions System is a fully automatic system developed by the Physics and Electronics Department of CEDEX. This system has a capability to address up to 256 
different sensors and is able to organise and record tests with all the 256 sensors participating.

Three different types of measurement tasks can be programmed with the help of this system:

- Static tests with the test cars at stand-still situation. These tests give the sensor readings without applied load. They are useful to obtain the reference readings of each sensor and to analyse the signal to noise ratio. During the static tests the system takes 400 measurements by sensor and calculates the mean value and associated standard deviation of the measure.

- The second type consist on the high resolution tests. These tests provide information about the dynamic behaviour of the selected sensor. It is possible to programme the sampling frequency and, conscquently, the sweep length. This allows to obtain fast and slow measures allowing to focus the mcasure on different aspects. During these tests the system obtains 32.000 measures of the selected sensor at 5 programmable sampling speeds going from 625 to 10.000 samples / second. The starting of the process can be synchronised with the passage of the test vehicle by the desired position sensor. A variable delay can by also added to centre the measure around the sensor.

- The third possibility consist on the normal dynamic tests. These tests require the selection of a family of sensors, being possible to include all 256 installed sensors in a single test. Once the sensor family has been selected, the transversal position of the cars can be also programmed. The test can be started by time or synchronised with the desired number of cycles of the selected vehicle. When the starting event (time / cycles) takes place and no failures are detected in the control of the cars, the test vehicles are placed on the transversal position programmed for the test, leaving the statistic control of transversal passages. Afterwards, the speed of the test vehicle is measured during one complete cycle and the sampling frequency is determined to obtain 200 measures in the sclected measuring length. The required delay after the starting event is also calculated to centre in the selected sensors the programmed measuring distance (usually, 10 meters). Once the test has been carried out the test results are transmitted and the control of the transversal position of the vehicles is transferred back to the control of statistical distribution of passages. Each test can be arranged for automatic repetition by cycles (one test every $\mathrm{n}$ cycles) or by time (one test cvery $\mathrm{n}$ seconds).

\section{MEASUREMENTS DATA BASE AND ANALYSIS.}

Once the test results have been transmitted to the central host mainframe where the test result files are analysed. The measuring curves of each sensor are firstly filtered to improve the signal to noise ratio. In a second stcp, the curves are classified according to characteristic mechanical parameters base on stress and strain magnitudes (maximum horizontal deformation produced by traction forces, maximum normal stress produced by the application of load, etc). Finally the curves are sorted and stored according to the values of the characteristic parameters.

Additional identification data is added for ulterior analysis. These identification data are: name of sensor, number of cycles accomplished by the test vehicles, pavement and environment temperatures, speed of the test vchicle, transversal position of the test vehicle and time stamping.

An specific application has been developed for computeraided analysis of measuring curves and parameters. This successful application of information technology has been developed by the Centre of Roads Studies of CEDEX. As an example, it is worth to mention here that as a result of the second pavements test at full scale, 120.000 curves have been analysed, classified and stored.

\section{SENSORS}

\subsection{Horizontal strain.}

This kind of sensor is based on the use of Strain Gages. These devices change its electrical resistance proportionally to its deformation: Both magnitudes are connected by the well known equation:

$$
\frac{\Delta R}{R}=k \cdot \frac{\Delta L}{L}
$$

Where:

$\mathrm{L} / \Delta \mathrm{L}$ : Length and length variation of gage conductor.

$\mathrm{R} / \Delta \mathrm{R}$ : Resistance and resistance change of gagc conductor.

$\mathrm{K}$ : $\quad$ Gagc factor.

The use of this sensor requires to consider carefully the following aspects:

- The resistance changes can also be due to temperature changes. This is effect is corrected through a coefficicnt affecting the Gage Factor and given by the provider of the Gage. It also can be corrected thanks to special Gagc assembly configurations providing automatic compensation of this effect. When this configuration for temperature compensation can not be used due to the fact that scveral Gages are required, then the temperature has to be measured and the Gage Factor has to be corrected accordingly.

- There is a shift on the Gage reference rcading, mainly due to the ageing of the components to which the Gage is fixed (adhesives, rcsins, ctc). This makes this kind of sensor unuseful for long-term measurements. Nevertheless, it can bc uscd without problems in dynamic measurements.

- In the case of bituminous mixtures, the Gage has to withstand extreme installation temperatures of about $160^{\circ} \mathrm{C}$. The same is valid for the adhesive and protection materials used. Accordingly, the Gage and associated materials have to be carefully selected according to this requirement. 
Differently from other applications where the strain gage is fixed directly to the surface of the infrastructure (metallic or concrete beams), in this case the gage is cmbedded inside the bituminous mixture. To do this, the gage is mounted over a support material that providing a good mechanical connection with the pavement internal structure and assuring a good orientation inside it.

With this purpose, the gages were assembled over a Kapton $300 \mathrm{HN}$ support of $125 \times 45 \mathrm{~mm}$.. To the Kapton layer mechanical elements were added assuring a fix contact with the bituminous mixture. These elements consisted on silicon sand granules of 0.64 to $0,32 \mathrm{~mm}$. size. The sand granules were fixed to the Kapton layer with Aralditc in a band of 15 mm. width.

Over a common Kapton shect two bands were mounted, far away to avoid interference. This asscmbly requires three connection threads ( $1 / 4$ bridge) and is completed with three external precision resistors for bridge balancing. The gages are of simple lattice, they are encapsulated and temperaturecompensated. They have the following nominal characteristics:

Range:

$\pm 5 \%$ of strain (referred to nominal length).

Non-linearity: $0,1 \%$ full scale.

Active length: $25 \mathrm{~mm}$.

Nominal resistance: $\quad 120 \pm 0,5 \Omega$

Gage Factor: $\quad 2,0$

Fatigue resistance: $\quad 10^{6}$ cycles of $\pm 1200 \mu \mathrm{dcff}$.

Working temperature: $-20^{\circ} \mathrm{C}$ to $+175^{\circ} \mathrm{C}$

This sensor has been specifically developed and fitted by the Centre of Roads Studies (CEC).

Considering the important role played in the test by this type of sensor and considering also its high breaking percentage during installation, great number of laboratory tests were carried with the aim of finding the most adequate materials and assembly procedures allowing the transducer to support the hard mechanical conditions during firm compaction and moisture degree.

We explain briefly downwards the assembly and installation procedures as they have becn carried out in the Instrumentation Laboratory of the Roads Studies Centre:

The support structure is prepared by cutting $300 \mathrm{HN}$ Kapton layers of $125 \times 45 \mathrm{~mm}$, as explained beforchand. The layer is submitted to a cleaning process with isopropilic alcohol and afterwards it is grasped to assure a better adherence. Next, a two components resin-based glue is applied on the Kapton and Gage surfaces, allowing the surfaces to dry during some minutes, then the Gages are placed over the Kapton layer. They are then fixed together by means of an assembly structure and submitted to a thermal treatment, applying heat in two steps: first from environment temperature to $160{ }^{\circ} \mathrm{C}$ with $5^{\circ} \mathrm{C} / \mathrm{min}$ gradient and secondly, the assembly is maintained at $160^{\circ} \mathrm{C}$ during 2 hours. Afterwards, the assembly is cooled at $50^{\circ} \mathrm{C}$ in the oven and is liberated of the pressing structure.
After the gage fixing process, the transducer is submitted to a hardening process at $200^{\circ} \mathrm{C}$ during two hours controlling the temperature gradient at the same rate of $5^{\circ} \mathrm{C} / \mathrm{min}$. Finally this basic asscmbly is cooled again at $50^{\circ} \mathrm{C}$. After visual inspection, it is mounted over an additional teflon layer able to work at temperatures in between $-269^{\circ} \mathrm{C}$ and $+260^{\circ} \mathrm{C}$. The thread terminals are cleaned with the help of a Solvent and soldered.

This transducer trends to fail because of the high moisture degree. To avoid that and assure a correct bchaviour during the whole test period, several moisture protection treatments are applied. This is reached thanks to the application of a cover sheet over the gages and soldering points followed by a 2 hours drying process at $24^{\circ} \mathrm{C}$. Finally, all the surface occupicd by the strain gages and soldering points is covered by a new $2 \mathrm{~mm}$ thick silicone layer of RTV type. This layer also covers the entrance of the connection cable including its external seal. This silicone layer is dried at $24^{\circ} \mathrm{C}$ during 24 hours.

At last, a final anti-moisture layer is applied over the band between the silicon shcet and the Kapton layer. This protective cover is also of silicon RTV type dried at $24^{\circ} \mathrm{C}$ during one hour.

The final aspect of the transducer after completion of all mounting process is shown in the picture of Fig. 3. In this Figure the two sand-granule bands assuring good mechanical contact with the bituminous mixture cab be appreciated.

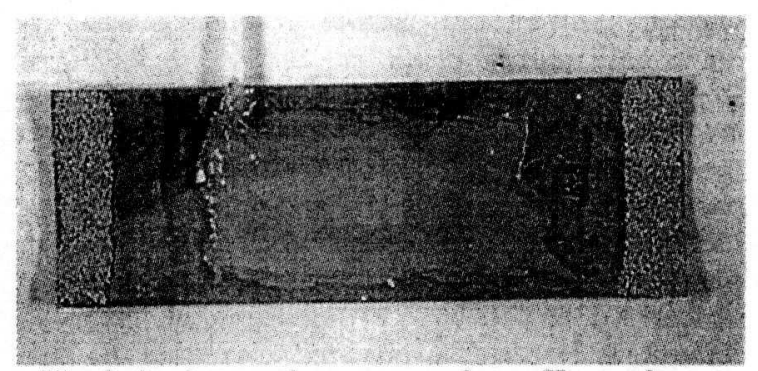

Fig. 3: Strain transducer mounted over Kapton layer.

The transducer is installed with the silicon cover upwards to avoid possible damages produced by the penetration of sharp particles integrated in the bituminous mixture.

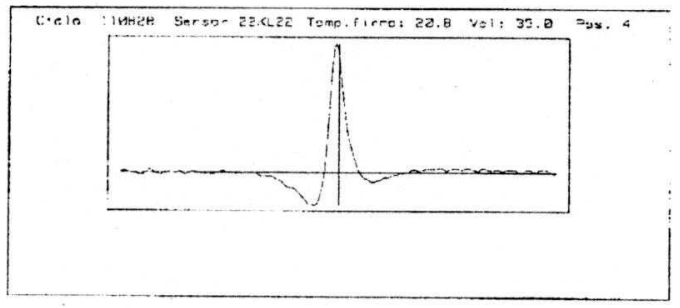

Fig. 4: Response of a Kapton layer transducer to a passage of the test wheel.

The typical response of this sensor to the passage of the test wheel has the aspect shown in Figure 4. This curve has been recorded in a real test by the data logging system. 
5.2 Normal strains in the granular layers. Strains transmitted to the esplanade.

\subsubsection{LVDT based sensor.}

Two different scnsor are used to measure these magnitudes one is LVDT (Linear Variable Displacement Transformer) based and the second is based on strain gage transducers.

The functioning principle of the LVDT is well known. It is a mechanical transducer werc the displacement changes are transformed to a sinusoidal. voltage thanks to the use of cylindrical transformer with mobilc core. Thanks to its constitution this kind of transducer offers some advantages for displacement measurcments. These mainly are:

- They are friction and hysteresis free.

- They have an extremely linear behaviour allowing great signal amplification with the associated increase of resolution

- They quitc robust, assuring correct operation over the whole test period.

- Thcir measurement principle is not affected by temperature changes.

The mechanical design of this LVDT-based transducer can be customised to the application. In our case the transducer is formed by two metallic disks whose relative movements are measured by an LVDT intercalated between them. Each disk is fixed to a different extremity of the LVDT transducer. To avoid abnormal compressions produced by accumulation of materials the upper disc offers an open structure with a driving-wheel shape.

The assembly of this transducer is shown in the picture of Fig. 5.

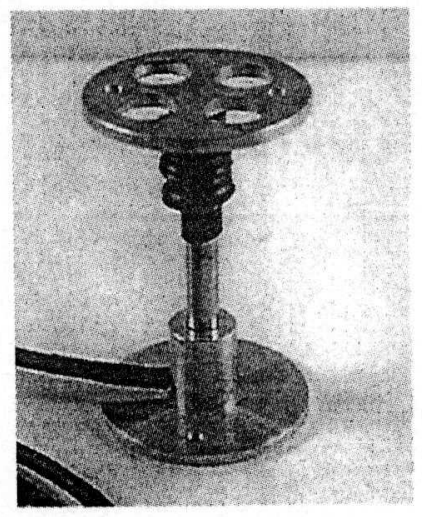

Fig 5.: Normal strain transducer based on LVDT.

The LVDT selected for the assembly of this transducer, has the following characteristics:

Measurement Range: $\pm 12.5 \mathrm{~mm}$.

Resolution: $\quad \pm 0,005 \mathrm{~mm}$.

Non-linearity: $\quad \pm 0,25 \%$ of full scale

Time constant: $\quad 0,01 \mathrm{sec}$. for a $90 \%$ of full scale variation.

Working temperature: $-20^{\circ} \mathrm{C}$ to $+125^{\circ} \mathrm{C}$.

Protection class: IP68.
The assembly of this sensor has been improved for the last test by the use of two threaded rods parallel to the main axle of the sensor. These two rods allow to situate the transducer at the desired high before introducing it into the hole drilled in the firm to host the transducer. Once introduced, the transducer is covered by a compacted bituminous layer.

Once the correct placement of the sensor is assured by test, the two rods are removed and the correct position is tested again. In the assembly procedure used in previous tcsts, the position of the sensor changed during the compacting process of the pavement. Obviously, this movement had an associated loss of measurement range.

\subsubsection{Strain Gage based sensor:}

The transducer based on strain gages has been fully developed by the Instrumentation Laboratory of the Roads Studies Centre and is consequently an innovation in the measurement of normal strains. It consist on a metal strip with two strain gages fixed along its main axis. This strip is fixed on both ends to a metal discs and the functioning principle is similar to the previous LVDT based sensor with the difference that now the disc displacements are translated into a bending of the metal strip, which is dully calibrated.

The use of metal strips as transducer offers two main difficultics:

The first difficulty appears in the installation procedure. This sensor has to be placed on site after the compacting process of the firm, for this reason it is necessary to proceed with a second manual compacting process. This process is quite delicate and it is difficult to assure the correct transducer function after it.

The second difficulty consist on the impact of the surrounding environment on the sensor affecting its behaviour. This is because of the environment moisture and because the penetration of fine aggregates blocking all mechanisms up to the point of producing its immobilisation.

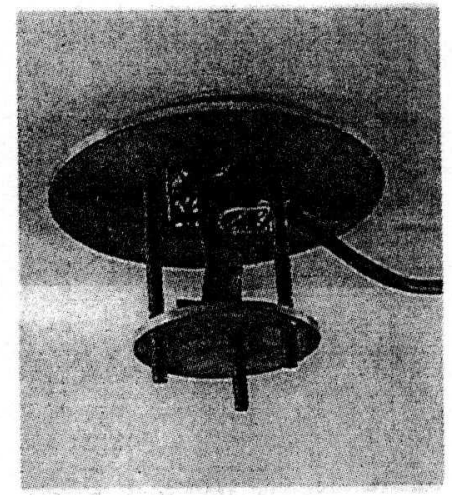

Fig. 6: Normal strain transducer based on Strain Gages 
The new assembly procedure designed in the Instrumentation Laboratory avoids both problems. It is shown in the picture of Figure 6.

The mechanical couplings have been designed to avoid the installation problems by laying the inferior disc on the surface of the previously compacted firm avoiding an ulterior manual compacting process.

The moisture and aggregate penetration problems are solved by surrounding the sensor with an elastic silicon cover. The moulding box of this silicon cover is used to isolate the transducer from the surrounding firm aggregates

\subsection{Pressures in the granular layers. Pressure transmitted to the esplanade.}

After the unavailability of direct methods to measure pressure, this magnitude is measured by indirect methods through strain sensors. The sensor consist on an elastic diaphragm which is deformed under the pressure action. To avoid inaccuracies due to the eccentricity of the cell or due to punctual loads produced by aggregates, a viscous liquid is used as interface between the surface of pressure application and the measurement diaphragm. This liquid distributes uniformly the pressures acting on the sensor' surface. Usually, absolute pressure transducers are used.

The functioning principle is based on the measurement of the diaphragm deformations by Strain Gages. The ratio between output voltage and applied pressure depends on the type of the terrain where the sensor is placed. To avoid this dependency, it is highly desirable that the ratio between the soil and diaphragm rigidities to be as low as possible. It is also quite convenient for the same purpose that the ratio between the thickness and cell diameter (slenderness) to bc also as low as possible.

In any case, a Laboratory calibration is required to reach the required accuracy. This calibration has to be undertaken on the same field conditions. The pressure transducers selccted for the measurement of esplanade pressures are of cylindrical shape type. The main characteristics of this sensors, are the following:

Measurement Range: $\pm 5 \mathrm{Kg} / \mathrm{cm}^{2}$.

Resolution: $\quad \pm 0,025 \mathrm{Kg} / \mathrm{cm}^{2}$.

Non-linearity: $\quad \pm 0,1 \%$ of full scalc

Time constant: $\quad 0,01 \mathrm{sec}$. for a $90 \%$ of full scale var.

Mcasuring diameter: $160 \mathrm{~mm}$.

Working temperature: $-30^{\circ} \mathrm{C}$ to $+80^{\circ} \mathrm{C}$.

Slenderness: $\quad \varepsilon<0,15(\varepsilon=h / \Phi)$

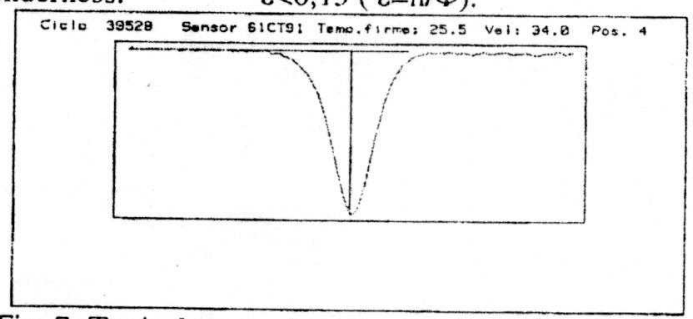

Fig. 7: Typical measuring curve generated by pressure sensors.
Figure 7 shows a typical curve produced by this sensor under the passage of the test wheel.

\subsection{Total deflection.}

To measure the movement of a point on the firm surface, a reference point is required. This reference can be interior to the pavement and in this case displacement transducers are used. The reference can also be exterior and then optical methods are required. Additionally, the possibility of using accelerometcrs for dynamic measurements, could be considered. This last alternative results espccially adequate to measure impact responses.

The most frequently method used is based on displacement transducers. This method has been also adopted in our test and has been implemented with LVD'T sensors.

The device is placed vertically into a borehole practised previously in the pavement. Along the axis of the hole, a rod is introduced and fixed to the concrete support of the track giving in this way a reference. The upper part of the sensor remains accessible from the surface and it is adjusted to the surface level. The lower part of the sensor is attached to the rod.

These transducers with mechanical couplings have the following main characteristics:

Measurement Rangc: $\pm 2.5 \mathrm{~mm}$.

Resolution: $\quad \pm 0,005 \mathrm{~mm}$.

Non-linearity: $\quad \pm 0,25 \%$ of full scale

Time constant: $\quad 0,01 \mathrm{sec}$. for a $90 \%$. of full scale variation.

Working tempcrature: $-40^{\circ} \mathrm{C}$ to $+100^{\circ} \mathrm{C}$.

Protection class: IP68.

\subsection{Temperature.}

The most frequently used temperature sensors arc based on thermo-resistors. The resistance thermometers use a detector element whose electrical resistance depends on the temperature. Due to its good linearity and stability, platinum is the preferred material to build the measuring resistor.

The selected sensors for the measurement of pavement and environment temperatures are platinum thermoresistors protected by stainless still covers. They offer the following characteristics:

$\begin{array}{ll}\text { Mcasurement Range: } & -20^{\circ} \mathrm{C} \mathrm{C}+70^{\circ} \mathrm{C} \\ \text { Resolution: } & \pm 0,25^{\circ} \mathrm{C} . \\ \text { Non-linearity: } & \pm 0,25 \% \text { of full scale } \\ \text { Time constant: } & 0,01 \text { sec. for a } 90 \% \text { of full scalc } \\ & \text { variation. }\end{array}$

The transducers used for the mcasurement of the environinent temperature are protected by stainless covers against sun radiation, rain and snow. The cover 
allows free air circulation thanks to the hollows practiscd on the cover.

\subsection{Phreatic level detectors.}

These transducers are based on electrical signal transducers providing an electrical current as output. They are mounted in complete bridges of Strain Gages, current feed. They offer the following characteristics:

Measurement Range: $2.5 \mathrm{~m}$.

Resolution: $\quad \pm 10 \mathrm{~mm}$.

Non-linearity: $\quad \pm 0,25 \%$ of full scale

Time constant: $\quad 1$ sec. for a $90 \%$ of full scale variation.

Working temperature: $-25^{\circ} \mathrm{C}$ to $+80^{\circ} \mathrm{C}$.

Protection class: $\quad$ IP68.

\section{CONCLUSSIONS}

Since the year 1.998 threc pavement tests have been carried out in the Full Scale Test Track of the Road Studies Centre. During these tests the stress and strain magnitudes are measured under load conditions. This allows to collect useful data for pavement modelling.

This task has been accomplished thanks to an interrupted R\&D work started with the first test. This work has consisted mainly in the search of adequate sensor to measure each magnitude. Specific sensors have been developed and improved installation methods have been specified. This innovation work has produced good and useful results in the roads instrumentation field.

\section{REFERENCES}

[1] Pallás Areny, Ramón "Sensores y acondicionadores de señal". Ed Marcombo 1994.

[2] S. Figliola, E. Beasley. "Thcory and design for mechanical measurements". Ed Wyley and sons 1991.

[3] CEDEX. Informe técnico de la Instrumentación de la Pista de ensayos acelerados de firmes del Centro de Estudios de Carretcras.1996. 